\title{
Blue diaper syndrome
}

INSERM

\section{Source}

INSERM. (1999). Orphanet: an online rare disease and orphan drug data base. Blue diaper syndrome. ORPHA:94086

Blue Diaper syndrome is a hereditary metabolic disorder characterised by hypercalcaemia with nephrocalcinosis and indicanuria. 